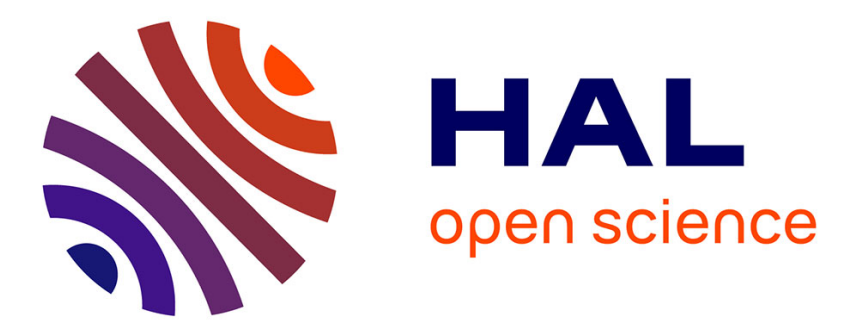

\title{
A Web-Based Information Market to Support Policy Decision Making
}

Niki Nikolakakou, Efthimios Bothos, Gregoris Mentzas

\section{To cite this version:}

Niki Nikolakakou, Efthimios Bothos, Gregoris Mentzas. A Web-Based Information Market to Support Policy Decision Making. 8th International Conference on Electronic Participation (ePart), Sep 2016, Guimarães, Portugal. pp.153-161, 10.1007/978-3-319-45074-2_12 . hal-01637233

\section{HAL Id: hal-01637233 \\ https://hal.inria.fr/hal-01637233}

Submitted on 17 Nov 2017

HAL is a multi-disciplinary open access archive for the deposit and dissemination of scientific research documents, whether they are published or not. The documents may come from teaching and research institutions in France or abroad, or from public or private research centers.
L'archive ouverte pluridisciplinaire HAL, est destinée au dépôt et à la diffusion de documents scientifiques de niveau recherche, publiés ou non, émanant des établissements d'enseignement et de recherche français ou étrangers, des laboratoires publics ou privés.

\section{(c)(1)}

Distributed under a Creative Commons Attribution| 4.0 International License 


\title{
A web-based Information Market to Support Policy Decision Making
}

\author{
Niki Nikolakakou ${ }^{1}$, Efthimios Bothos ${ }^{1}$ and Gregoris Mentzas ${ }^{1}$ \\ ${ }^{1}$ Institute of Communications and Computer Systems, \\ National Technical University of Athens, Greece \\ \{nikolaka, mpthim, gmentzas\}@mail.ntua.gr
}

\begin{abstract}
Reliable and timely information about current economic and environmental conditions is crucial for policy makers to take decisions and for steering agents' expectations formation about the state of the economy. While the usefulness of monitoring expectations, opinions and sentiments of economic agents is undoubted, one can argue that existing indices are based on a selected number of surveys and a low monitoring frequency resulting in a partial view of more complex dynamics. In this paper we present a web based tool based on the concept of Information Markets that can be used to aggregate expectations on policy indices and provide accurate and timely information to policy makers and policy modellers.
\end{abstract}

Keywords: Policy Modelling, Information Markets, Predictions of policy indices.

\section{Introduction}

Reliable and timely information about current economic and environmental conditions is crucial for policy makers to take decisions and for steering agents' expectations formation about the state of the economy [1]. Nowadays several institutions in industrialized countries collect data regarding expectations on the outcome of future events and periodically (monthly, quarterly etc.) release aggregated indices. Many policy makers and modellers take recourse to survey evidence to measure current conditions in the economy; policy related reports frequently point to survey evidence when describing the current macroeconomic situation. For example, the Survey of Professional Forecasters (SPF) and the Purchasing Manager Indices (PMI) have gained great attention as they are regularly mentioned in monetary policy communications [2]. Other approaches rely on data of higher frequencies, including financial series and monthly data on real economic activity. The first category is often labelled as 'soft' data, while the latter as 'hard' indicators of real activity that measure certain components directly (e.g. industrial production as evidence of the GDP). Soft data are available promptly, while real activity data are published with a significant delay. On the other hand, the hard data contain more precise signals for indices [2]. Related work (see e.g. [3]) shows that these indices closely follow the economic

adfa, p. 1, 2011.

(C) Springer-Verlag Berlin Heidelberg 2011 
situation as described by variables, like GDP, inflation or interest rates, and even anticipate turning points in the economic cycle.

While the usefulness of monitoring expectations, opinions and sentiments of economic agents is undoubted, one can argue that existing indices are based on a selected number of surveys and a low monitoring frequency resulting in a partial view of more complex dynamics. For example, the first (advance) data release of GDP growth for the current quarter is released about six weeks after the end of the quarter [4]. In order to gauge the continuously evolving state of the real economy alternative sources of information need to be employed. Moreover, survey based methodologies are often not incentive compatible and therefore can be of low precision in revealing the 'real' preferences and expectations of experts and the population at large [5].

In this paper we present a web based tool based on the concept of Information Markets that can be used to aggregate expectations on policy indices and provide accurate and timely information to policy makers and policy modellers. The paper proceeds as follows. Section 2 provides an overview of Information Markets, Section 3 describes the design elements of our tool while Section 4 presents a walkthrough usage scenario. In Section 5 we provide insights on the current status of our work and we conclude Section 6 with our final remarks and next steps.

\section{Overview of Information Markets}

Information Markets (IMs) rest on the concept of bringing a group of participants together via the Internet and allowing them to trade shares of virtual contracts which yield payments based on the outcome of unknown future events [6]. Contract prices provide a reasonable estimate of what the participants (traders) in aggregate believe to be the probability of the future events, and as such, markets are able to generate forecasts. IMs are designed and run for the primary purpose of mining and aggregating scattered among traders information and subsequently use of this information in market values in order to make predictions about specific future events [7].

There are various theories supporting the information and expectations' aggregation efficiency of IMs and markets in general. According to the subjective theory of probability [8], probability is a rate at which an individual is willing to bet on the occurrence of an event. As it is natural for humans to consider probabilities and bets, an Information Market can provide a space where participants can reveal their probabilities of future events by thinking in terms of wagering their money to alternate future states of the world. Moreover, the efficient markets' hypothesis states that when a market reaches equilibrium, it reflects all available information about future events into market prices [9]. The efficient market hypothesis requires that participants have rational expectations, that on average the population is correct (even if no single participant is) and whenever new relevant information appears, the participants update their expectations appropriately. An implication of the efficient market hypothesis is that share prices reflect their true expected value, therefore markets provide accurate forecasts of their underlying commodities and securities. Last but not least, recent research shows the connections between cost function based IMs and online learning [10]. 
IMs are considered an example of collective intelligence and they are characterized by their accuracy, easy deployment, and ability to dynamically incorporate new information available to traders by continuously adjusting an event's price [11]. However despite the benefits expected, the public sector seems rather reluctant to introduce IMs in order to improve public decision making. In [12] information markets are proposed as a new tool that will revolutionize governance, while in [13] a framework and the main characteristics an information market should fulfil in order to perform well in situations relevant for policy decision making are described. Recently, the use of information markets has been suggested as a tool which can foster the participation of citizens in European public policy [14] or support macro-economic forecasts for governments [15].

\section{The PolicyOracle Information Market}

PolicyOracle is an Information Market which provides the mechanisms to aggregate participants' expectations and provide forecasts of economic, environmental and energy indicators in order to support policy making. It relies on play money as the resource for buying or selling contracts, which means that participants receive a number of points that can be used for trading upon their registration. This design was adopted as previous research has shown that the accuracy of play money Information Markets is similar to those that use real money, while the use of real money even for research purposes has to consider legal issues. Furthermore, PolicyOracle resembles a virtual stock market which means that a number of market design elements were considered, including: the market mechanism which affects how transactions are processed, the type of contracts that determine what expectations are aggregated and the participants who perform transactions and set the market prices.

\subsection{Market Mechanism}

The market mechanism determines how the buy and sell orders that participants place are cleared. Similarly to the first version of the Information Market tool, PolicyOracle uses a mechanism based on an Automated Market Maker (AMM). This means that all transactions are processed by the AMM which is practically a function that determines the cost or gain of buy and sell transactions respectively. In more details, when a participant places a buy or sell order for a particular contract, the system validates the order and it is always ready to process it, acting as an "always there" buyer and seller. The AMM price function in PolicyOracle follows the work of [16] and simulates real life supply and demand conditions. If we let $s_{i}$ be the net amount of shares a given contract that has been sold, then the price of contract $i$ is given by formula (1) where $b$ represents a scaling factor that controls the market's depth and determines the rate of price changes when traders buy or sell shares from the AMM (low values of $b$ cause greater price fluctuations and higher volatility) and $c$ represents the maximum price of an outcome. 


$$
P_{i}=\frac{c e^{s / b}}{\sum_{k} e^{s k^{\prime b}}}
$$

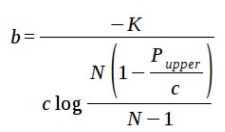

In order to facilitate trading and make users feel comfortable with contract prices, we selected a span of prices between 0 and 100. So, we set $c=100$ and the $P_{i}$ prices sum to 100. Another aspect that needs to be considered before running a market refers to the value of the constant $b$. As mentioned above, the elasticity constant $b$ controls how much prices change after a transaction. Setting $b$ requires special attention as a low value can lead to great price fluctuations after a transaction while a high value can cause low price movements which will not reflect the aggregate opinions of the participants adequately. We follow the approach described in [17] and calculate a variable price of $b$, based on the total amount of money $\mathrm{K}$ which is available in the market and the desired target upper price $P_{\text {upper }}$ of a contract which is given if all of the money is invested in that contract. The value of $b$ is given by formula (2) where $N$ represents the possible mutually exclusive contracts in the market and we set $P_{\text {upper }}=99$. In order to keep the market elasticity constant, we adjust and re-calculate the $b$ value each time a new trader registers in our platform (at this time new money is introduced into the market as the trader receives an initial amount of 20000 points) as well as when a question is resolved and contracts are rewarded (when a contract is rewarded new money is introduced into the market as winners receive money).

\subsection{Contracts}

Contracts represent the mutually exclusive possible outcomes of policy questions and are the tradable assets of the market. For example the question "Will the inflation in Europe rise in 2016" may have two answers, "YES" or "NO" and thus two contracts. Contracts expire when the event they refer to is realized and provide a payoff value. We follow the "winner-takes-all" payoff rule which means that a contract is worth 100 points if the outcome of the event the contract represents is realized, and 0 points otherwise.

In order to be able to aggregate information on a variety of policy indices, we have designed three types of questions: binary, multiple choice and multiple interval. Binary questions have two contracts one referring to a positive answer, the YES contract, and another referring to the negative answer, the NO contract. Market participants invest on the YES answer (contract) of the question if they believe that the GDP will be higher than 13.920B euros, else on the NO answer (contract). This kind of questions are suitable for aggregating expectations on the trends of policy variables.

Multiple choice and multiple interval questions can have two or more answers and consequently two or more contracts. An indicative example of such a questions is "What will the official quarterly GDP growth rate for Q1 2015 in Spain be?". The possible answers depend on the values the policy maker or modeller wishes to set and receive feedback. In our example there can be 10 answers each corresponding to certain range as follows: '<- $0.9 \%$ ', ' $-0.9--0.5 \%$ ', ' $-0.4-0.1 \%$ ', ' $0.0-0.4 \%$ ', ' $0.5-$ $0.9 \%$, ' $1.0-1.4 \%$, ' $1.5-1.9 \%$ ', ' $2.0-2.4 \%$ ', ' $2.5-2.9 \%$ ', '>2.9\%'. 
In all cases described above, contract prices range between 0 and 100 and reflect the likelihood of the event, that the answer which the contract represents, to be realized.

\subsection{Participants}

Participants access the system through a web interface and we have defined three user roles who have access to different functionalities: administrators, traders and visitors. Administrators set up the questions and the answers. They are the policy makers and policy modellers who want to have the aggregated expectations of experts and interested stakeholders. Traders express their expectations by signing up and selecting the contracts which they want to trade. Visitors monitor the likelihood of the events defined in the market. The following table summarizes how different stakeholder groups can use PolicyOracle.

Table 1. Stakeholder groups and use of PolicyOracle

\begin{tabular}{|l|l|}
\hline \multicolumn{1}{|c|}{ Stakeholder group } & Use of PolicyOracle \\
\hline $\begin{array}{l}\text { Policy Makers (Politicians, } \\
\text { European Central Bank, Bank } \\
\text { of England) }\end{array}$ & $\begin{array}{l}\text { They are the key actors who take the actual decisions. } \\
\text { PolicyOracle supports them by offering access to experts' } \\
\text { aggregated expectations. }\end{array}$ \\
\hline $\begin{array}{l}\text { Policy Advisors (e.g. Global } \\
\text { Climate Forum, German } \\
\text { Watch, National Central } \\
\text { Banks of the Eurozone) }\end{array}$ & $\begin{array}{l}\text { They are the actors who support policy makers in their } \\
\text { decisions. They may engage stakeholders (e.g. industry } \\
\text { representatives) in discussions on the impact of alternative } \\
\text { policy options. PolicyOracle supports them by offering } \\
\text { access to experts' aggregated expectations. }\end{array}$ \\
\hline $\begin{array}{l}\text { Industry (Large Enterprises } \\
\text { (e.g. Siemens, RWE, Allianz } \\
\text { etc.) }\end{array}$ & $\begin{array}{l}\text { They are actors who influence the opinion of policy advisors } \\
\text { and policy makers. }\end{array}$ \\
\hline $\begin{array}{l}\text { Civil Society ( } \\
\text { Environmental NGOs (e.g. } \\
\text { WWF), civil society actors } \\
\text { like unions (e.g. IG BAU)) }\end{array}$ & $\begin{array}{l}\text { They are institutions and organizations that manifest interests } \\
\text { and will of citizens. } \\
\text { PolicyOracle allows them to express expectations on policy } \\
\text { variables or monitor the results. }\end{array}$ \\
\hline $\begin{array}{l}\text { Citizens (SME owners, Public } \\
\text { servants, Young generation, } \\
\text { Employees) }\end{array}$ & $\begin{array}{l}\text { PolicyOracle allows them to express expectations on policy } \\
\text { variables or monitor the results. }\end{array}$ \\
\hline $\begin{array}{l}\text { Academia (Universities and } \\
\text { research organizations) }\end{array}$ & $\begin{array}{l}\text { PolicyOracle allows them to express expectations on policy } \\
\text { variables or monitor the results. }\end{array}$ \\
\hline
\end{tabular}

\section{A Walkthrough Scenario}

In this section we show the main functionalities of PolicyOracle and how these can be used for the aggregation of expectations on macroeconomic and environmental policy indices.

Assume that a policy expert named John logs into the system. He is provided with a list of available questions as illustrated in Fig. 1-A. By clicking on the 
question he is interested in, the user is directed to the trading screen where he can provide a prediction by investing his play money. By default, he sees the simple view of the trading screen (Fig. 1-B). In this view, he can provide an estimate about a possible outcome using a likert-scale like interface. The available options span from "likely" to "almost sure" depending on his belief in a 5 point interval. John is more experienced with markets and trading interfaces and chooses the advanced view (Fig. 1-C). This view resembles a stock exchange where John can set the exact amount of shares she would like to buy or sell.

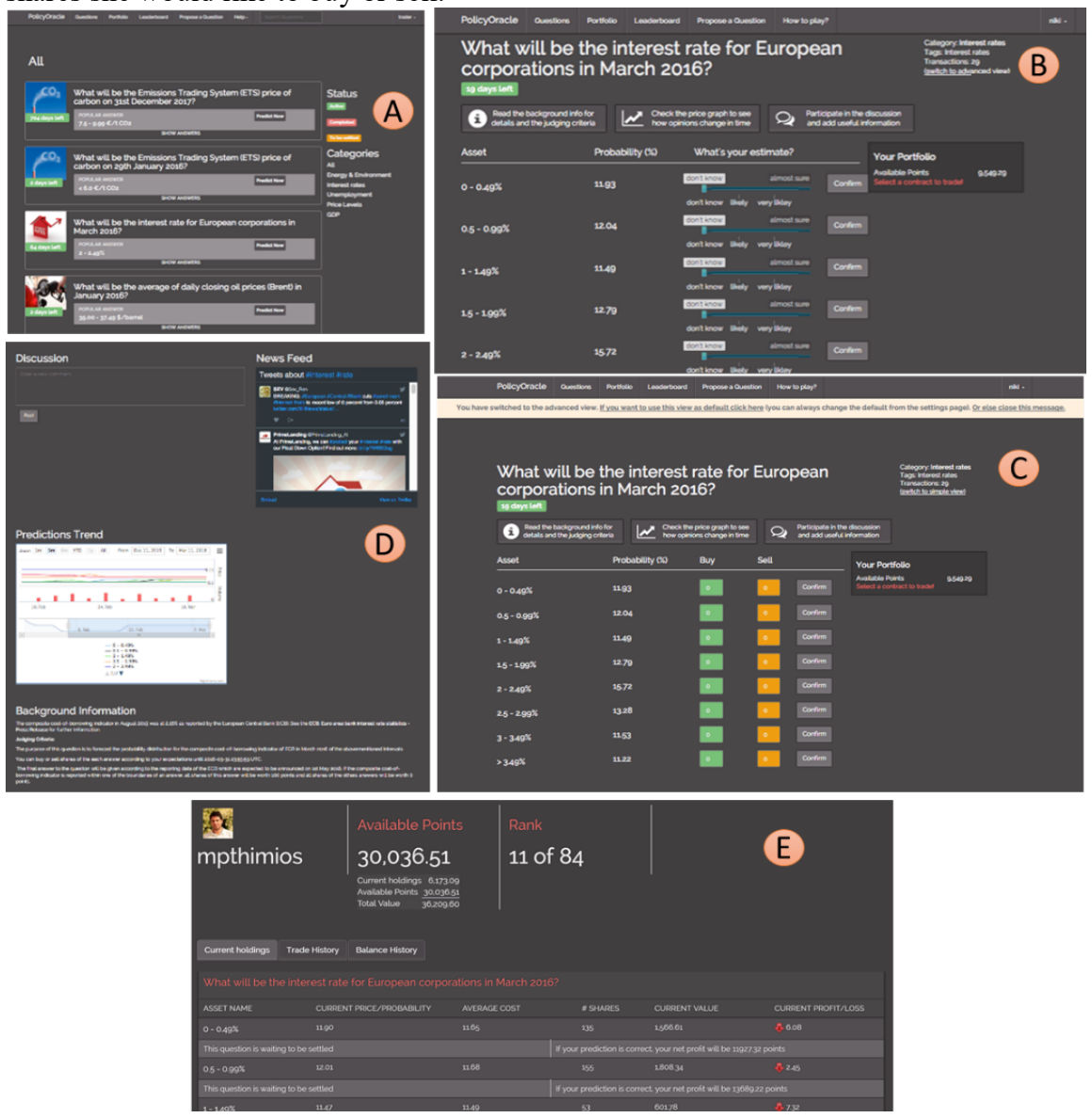

Fig. 1. Overview of the PolicyOracle main screens and functionalities.

The quantity of the shares is entered in the relevant boxes of each contract (i.e. the answers to the questions). Selling without owning an amount of shares is not permitted by the system. Before confirming a transaction, the system provides information related to the costs or gains of the transaction and the new contract prices. If John agrees, he confirms the transaction and his portfolio is updated. The trading 
screen provides additional information regarding the selected question. John can see how many days left while the question is open. Furthermore, there is information regarding the category of the question, relevant tags as well as the number of transactions.

John has a portfolio consisting of contracts and play money. As shown in Fig. 1$\mathrm{D}$, John can see the total value of his account, including the current value of his holdings and the available points. Moreover, the user can view his rank in comparison to other users. The market is a form of a prediction contest in order to foster participation. Other information includes a list of the contracts $\mathrm{s} /$ he currently owns is presented, together with the current profit/loss, the quantity of holding shares as well as the average cost of his transactions. The "sell" button is provided beneath each holding, so John has the option to sell his stake in case he changes his opinion.

In Fig. 1-E, the tool provides social functionalities that enable discussions and posts on twitter. He can provide comments and participate in discussions, enabling information and opinion exchange. A Twitter News Feed based on keywords related to the question is displayed in order to provide frequently updated social media information. Moreover, price charts show fluctuations in the prices of contracts as well as the trading volume over time. Finally, a section with background information provides a detailed description of the question as well as links to external information sources.

\section{$5 \quad$ Current Status and First Results}

Our tool is online at the http://experts.policyoracle.org url and is currently being used by stakeholders in the context of the SYMPHONY project (http://projectsymphony.eu/). We have already defined a number of indices in collaboration with policy modellers who participate in the aforementioned project, which have been introduced as questions in our Information Market. The indices are related to macroeconomic and energy variables, and are the following:

- Gross Domestic Product (GDP): this is an aggregate measure of production equal to the sum of the gross values added of all resident, institutional units engaged in production. GDP estimates are commonly used to measure the economic performance of a whole country or region and can affect several economic policies, e.g. related to public investments and taxes.

- Consumer Price Index (CPI): this index measures changes in the price level of a market basket of consumer goods and services purchased by households. CPI determines the real value of wages, salaries and pensions for regulating policies related to prices and deflating monetary magnitudes to show changes in real values.

- Inflation Rate which shows the change of general price level of goods and services in an economy over a period of time. To ensure stability, current economic policies target for a steady and low inflation. Inflation forecasts determine how economic authorities (e.g. central banks) design and implement their monetary policies by setting interest rates, open market operations, and banking reserve requirements. 
- Unemployment Rate: this is a measure of the prevalence of unemployment and it is calculated as a percentage by dividing the number of unemployed individuals by all individuals currently in the labour force. Knowledge of unemployment tendencies can determine the monetary and fiscal policies for reducing unemployment caused by recessions (also termed as demand side policies).

- Interest Rate: this is a measure of the cost-of-borrowing indicator for new loans to corporations.

- Oil prices: This refers to crude oil prices, the fluctuations of which affect monetary policies.

- Electricity prices: This index shows the changes of prices in the wholesale electricity market. Electricity is a very special commodity as it is economically non-storable, and power system stability requires a constant balance between production and consumption. At the same time, electricity demand depends on weather and the intensity of business and everyday activities. Low electricity prices improve industrial competitiveness and consumer's welfare, thus accurate forecasts can help policy makers to devise policies which will keep prices at low levels.

The questions on macroeconomic indices have been implemented for Spain, Italy, Germany, Greece and the EU as a whole. The energy related questions have been implemented for the EU as whole. Currently 84 users have registered and are performing transactions; we expect to have an analysis of the first results in the coming months.

\section{Conclusions \& Future Work}

In this paper we presented a tool based on the concept of Information Markets in order to aggregate expectations on policy indices. We have presented its design elements, including the market mechanism, the contracts which represent answers to questions on the future value of policy indices and the type of participants including the benefits they can acquire from such a tool. A walkthrough scenario showed how our tool can be used to aggregate information related to the policy indices in the form of transactions in the Information Market. Last, we have selected a first set of macroeconomic and energy related indices which are relevant for policy decision making. The tools is already online and we plan to evaluate its usefulness to policy modelling and its prediction accuracy. To this direction we have already planned a series of focus group sessions with policy modellers where are going to showcase the tool and the results of the expectation aggregation process, in order to gather their feedback. Moreover as the real values of the policy indices are announced we plan to evaluate the tool's accuracy in predicting these values.

\section{$7 \quad$ Acknowledgements}

Research reported in this paper is partially funded by the European Commission project SYMPHONY (FP7 grant agreement no.: 611875). 


\section{References}

1. A. D'Agostino, B. Schnatz. Survey-based nowcasting of US growth: a real-time forecast comparison over more than 40 years, ECB working paper n. 1455 (2012).

2. M. Bańbura, G. Rünstler. A look into the factor model black box: publication lags and the role of hard and soft data in forecasting GDP. International Journal of Forecasting 27, no. 2 (2011), 333-346.

3. C. F. Manski, Measuring expectations. Econometrica, 72(5) (2004), 1329-1376.

4. R. Giacomini, Economic theory and forecasting: lessons from the literature. The Econometrics Journal, 18(2) (2015), 22-41.

5. T. Kranz, F. Teschner, C. Weinhardt. Combining Prediction Markets and Surveys: An Experimental Study. Proceedings of the 22nd European Conference on Information Systems (2014).

6. M. Spann, B. Skiera. Internet-based virtual stock markets for business forecasting. Management Science, 49(10) (2003) 1310-1326.

7. J. E. Berg, T. A. Rietz. Prediction markets as decision support systems. Information systems frontiers, 5(1) (2003) 79-93.

8. B. De Finetti. Logical foundations and measurement of subjective probability. Acta Psychologica, 34 (1970) 129-145.

9. B. G. Malkiel, E. F. Fama. Efficient capital markets: A review of theory and empirical work. The journal of Finance, 25(2) (1970) 383-417.

10. J. Abernethy, Y. Chen, J. W. Vaughan. Efficient market making via convex optimization, and a connection to online learning. ACM Transactions on Economics and Computation, 1(2) (2013).

11. E. Snowberg, J. Wolfers, E. Zitzewitz. Prediction markets for economic forecasting (No. w18222). National Bureau of Economic Research (2012).

12. R. Hanson Decision Markets for Policy Advice. In Patashnik, E.; and Gerber, A. (eds) Promoting the General Welfare, Brookings Institution Press, Washington D.C. (2006).

13. Ledyard J. Design of information markets for policy analysis. In Hahn, R.W.; and Tecklock, P.C. eds. Information Markets: a New Way of Making Decisions. The American Enterprise Institute Press, Washington DC (2006).

14. Millard J.; Nielsen M. M.; Warren R.; Smith S.; Macintosh A.; Tarabanis K.; Tambouris E.; Panopoulou E.; Efpraxia D., and Parisopoulos K. 2009. European eParticipation Report.

15. F. Teschner, S. Stathel, C. Weinhardt. A prediction market for macro-economic variables. In System Sciences (HICSS), 2011 44th Hawaii International Conference on 1-9 (2011).

16. R. Hanson. Logarithmic Market Scoring Rules for Modular Combinatorial Information Aggregation. The Journal of Prediction Markets, 1(1) (2007) 3-15.

17. H. Berg, T. A. Proebsting. Hanson's automated market maker. Journal of Prediction Markets, 3(1) (2009) 45-59. 